\title{
Risk factors for temporomandibular disorder: Binary logistic regression analysis
}

\author{
Bruno-Gama Magalhães ${ }^{1}$, Stéphanie-Trajano de-Sousa ${ }^{2}$, Victor-Villaça-Cardoso de Mello ${ }^{2}$, André-Cavalcante \\ da-Silva-Barbosa ${ }^{2}$, Mariana-Pacheco-Lima de-Assis-Morais ${ }^{2}$, Márcia-Maria-Vendiciano Barbosa-Vasconcelos ${ }^{3}$, \\ Arnaldo-de-França Caldas-Júnior ${ }^{4}$
}

\footnotetext{
${ }^{1}$ PhD student, Postgraduate Program in Dentistry, Universidade Federal de Pernambuco, Recife, Brazil

${ }^{2}$ Master's student, Postgraduate Program in Dentistry, Universidade Federal de Pernambuco, Recife, Brazil

${ }^{3}$ Doctoral degree in Nutrition, Universidade Federal de Pernambuco, Brazil; Adjunct professor, Universidade Federal de Pernambuco, Recife, Brazil

${ }^{4}$ Postdoctoral degree in Epidemiology in Public Health, University of London, UK; Doctoral degree in Preventive and Social Dentistry, Universidade de Pernambuco, Brazil; Adjunct professor, Universidade Federal de Pernambuco, Recife, Brazil
}

Correspondence:

Universidade Federal de Pernambuco

Centro de Ciências da Saúde

Departamento de Clínica e Odontologia Preventiva

Av. Prof. Moraes Rego, 1235

Cidade Universitária

50670-901-Recife, PE-Brazil

caldasjr@alldeia.com.br

Magalhães BG, de-Sousa ST, de Mello VVC, da-Silva-Barbosa AC, deAssis-Morais MPL, Barbosa-Vasconcelos MMV, Caldas-Júnior AF. Risk factors for temporomandibular disorder: Binary logistic regression analysis. Med Oral Patol Oral Cir Bucal. 2014 May 1;19 (3):e232-6. http://www.medicinaoral.com/medoralfree 01/v19i3/medoralv19i3p232.pdf

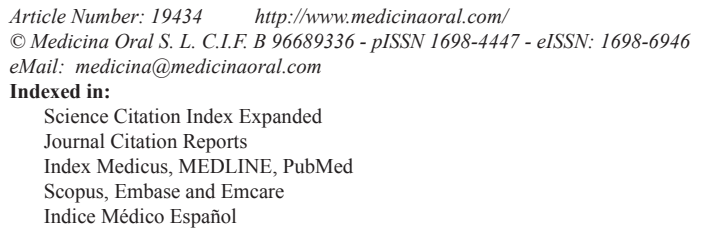

\begin{abstract}
Objectives: To analyze the influence of socioeconomic and demographic factors (gender, economic class, age and marital status) on the occurrence of temporomandibular disorder.

Study Design: One hundred individuals from urban areas in the city of Recife (Brazil) registered at Family Health Units was examined using Axis I of the Research Diagnostic Criteria for Temporomandibular Disorders (RDC/ TMD) which addresses myofascial pain and joint problems (disc displacement, arthralgia, osteoarthritis and oesteoarthrosis). The Brazilian Economic Classification Criteria (CCEB) was used for the collection of socioeconomic and demographic data. Then, it was categorized as Class A (high social class), Classes B/C (middle class) and Classes D/E (very poor social class). The results were analyzed using Pearson's chi-square test for proportions, Fisher's exact test, nonparametric Mann-Whitney test and Binary logistic regression analysis.

Results: None of the participants belonged to Class A, $72 \%$ belonged to Classes B/C and $28 \%$ belonged to Classes $\mathrm{D} / \mathrm{E}$. The multivariate analysis revealed that participants from Classes $\mathrm{D} / \mathrm{E}$ had a 4.35 -fold greater chance of exhibiting myofascial pain and 11.3-fold greater chance of exhibiting joint problems.

Conclusions: Poverty is a important condition to exhibit myofascial pain and joint problems.
\end{abstract}

Key words: Temporomandibular joint disorders, risk factors, prevalence. 


\section{Introduction}

Temporomandibular disorder (TMD) is a term used for a set of conditions that affect the temporomandibular joint and orofacial musculature $(1,2)$. TMD can cause stiffness, joint noises, restricted mandibular movements and orofacial pain (3). Orofacial pain is an important factor directly associated with oral health-related quality of life (4).

The prevalence rate of TMD is quite variable in the literature. Epidemiological studies estimate that 40 to $75 \%$ of the population worldwide exhibit at least one sign of TMD, such as joint noises, and 33\% exhibit at least one symptom, such facial or joint pain (5-7). A number of studies report a higher prevalence rate in the female gender as well as peaks in adolescence and early adulthood (8-11).

There is consensus on the multifactor etiology of TMD. The literature reports possible risk factors, such as stress, hormonal factors, genetic factors, ethnicity, social status and gender. However, this field of knowledge remains obscure and well-designed studies is needed to allow greater clarification of this condition (12-17). Socioeconomic factors play an important role in health. Income, schooling, occupation, economic status and social inequalities can hinder access to health services, information and exams necessary for the diagnosis and treatment of diseases (1).

The aim of the present study was to analyze the influence of socioeconomic and demographic factors (gender, economic class, age and marital status) on the occurrence of temporomandibular disorder.

\section{Material and Methods}

The present pilot study was carried out with a sample of 100 individuals aged 15 years or older from urban areas in the city of Recife (Brazil) registered at Family Health Units (FHU). No restrictions were made regarding gender or ethnicity. Multi-stage cluster sampling was performed to include the entire city. The selection of Basic Health Units was performed randomly by lots. To obtain the sample size for the principal study, we used a multi-stage sample technique, where we first used a cluster sampling to define the neighborhood in Health Districts, then a systematic sampling to choose the FHU, and for last 100 volunteers, were randomly selected among users of FHU.

Ethical approval for all stages was granted by the local research ethics committee (CAAE 05650512.9.0000.5208). All volunteers that agreed to be in the study signed the informed consent form.

The diagnosis of TMD was determined using Axis I of the Research Diagnostic Criteria for Temporomandibular Disorders (RDC/TMD) (18), which addresses myofascial pain and joint problems (disc displacement, arthralgia, osteoarthritis and oesteoarthrosis). Individu- als diagnosed with at least one of these conditions were classified as having TMD. Four examiners underwent a training and calibration exercise for the administration of the RDC/TMD. Intra-examiner and inter-examiner agreement were determined using the Kappa statistic ( $\mathrm{K}=0.90$ and 0.82 , respectively).

The socioeconomic status was determined using the Brazilian Economic Classification Criterion of the Brazilian Association of Research Companies. This classification uses education level of the head of the household; number of radios at home; number of refrigerators; washing machines and color TVs; availability of drinking water and sewage, number of rooms in the home (especially the number of washrooms) and the number of cleaning personnel who work in the home. ABEP scores vary from zero (the poorest) to 46 (the richest). The scores were transformed into social class categories.

Scores from 0 to 7 correspond to class E, 8 to 13 (class D), 14 to 22 (class C), 23 to 34 (class B), 35 to 46 (class A) (ABEP 2013). In 2013 the Brazilian Association of Research Companies has changed the categorization. Then, the actual classification is Class A1 and A2 (high socioeconomic level), B1 and B2 (medium-high socioeconomic level), $\mathrm{C} 1$ and $\mathrm{C} 2$ (medium-low socioeconomic level) and D-E Class (as a unique class - poor socioeconomic level).

For the association analyses, marital status was dichotomized as "married" (respondents in a stable union, whether living together or not) and "not married" (widowed, divorced, separated and never married). Age was dichotomized as " $\leq 30$ years" and "> 30 years", since the literature has pointed out 30 years as an age peak for RDC/TMD diagnoses in adults (19).

Statistical analysis

The Shapiro-Wilk test was employed to determine the distribution of the data (normal or non-normal). Categorical variables were analyzed using Pearson's chisquare test for proportions and Fisher's exact test for 2 $\mathrm{x} 2$ contingency tables. Continuous variables were analyzed using the nonparametric Mann-Whitney test. To determine associations between the dependent and independent variables we did a binary logistic regression analysis and variables with a p-value $<0.05$ remained in the final model. Odds Ratios (OR) and 95\% confidence intervals (CI) were calculated. The SPSS 17.0 program was used for all statistical analyses.

\section{Results}

One hundred individuals aged 15 to 70 years (mean: $34.76 \pm 13.47$ years; median: 32 years) participated in the present pilot study. The majority was over 30 years of age $(57 \%)$ and $83 \%$ were women. More than half of the sample was not married (53\%). Regarding economic class, none of the participants belonged to Class A, $72 \%$ belonged to Classes B/C and $28 \%$ belonged to Classes D/E. 
Fourteen percent of the participants were diagnosed with myofascial pain; $26 \%$ were diagnosed with disc displacement and $18 \%$ were diagnosed with joint problems (arthralgia, osteoarthritis and osteoarthrosis). Economic class was significantly associated with a diagnosis of myofascial pain; a greater proportion of individuals with this symptom belonged to Classes $\mathrm{D} / \mathrm{E}$ (28.6\%). No statistically significant associations were found between myofascial pain and gender, age or marital status (Table 1).

Fisher's exact test revealed no statistically significant associations between disc displacement and gender, age, economic class or marital status (Table 2).

Economic class and marital status were significantly associated with joint problems (arthralgia, osteoarthritis and osteoarthrosis). The largest proportions of individuals with joint problems were married (23.4\%) and belonged to economic classes D/E (42.9\%). No statistically significant associations were found between joint problems and gender or age (Table 2).

Multivariate analysis was performed using the binary logistic regression model to determine the $\mathrm{OR}$ for patients with and without TMD. Gender, age, economic class and marital status were incorporated into the model for myofascial pain. The Hosmer-Lemeshow test was used to determine the goodness of fit of the model, with a p-value $>0.05$ demonstrating that the model fit the data. The multivariate analysis revealed that economic class was associated with a diagnosis of myofascial pain, as participants from Classes D/E had a 4.35-fold greater chance of exhibiting myofascial pain (Table 3).

The multivariate analysis revealed that social class and a diagnosis of myofascial pain were associated with joint problems. Individuals belonging to Classes D/E had an 11.3-fold greater chance of exhibiting joint problems (Table 4).

\section{Discussion}

Temporomandibular disorder is a widely studied, complex subject. However, a number of gaps in knowledge on this condition remain to be filled. The different etiologies discussed in the literature continue to be the subject of debate and disagreement among researchers and this lack of consensus has hampered the establishment of effective treatment protocols. Epidemiological studies are useful for the management of healthcare services by allowing

Table 1. Distribution of participants regarding myofascial pain according to gender, age, economic class and marital status.

\begin{tabular}{|l|l|c|c|c|c|c|c|c|}
\hline \multirow{2}{*}{ Variables } & \multicolumn{4}{|c|}{ Myofascial pain } & \multicolumn{3}{c|}{ Total } & \multirow{2}{*}{ p-value } \\
\cline { 3 - 9 } & Yes & \% & No & \% & n & \% & \\
\hline \multirow{2}{*}{ Gender } & Male & 1 & 5.9 & 16 & 94.1 & 17 & 100.0 & \multirow{2}{*}{0.263} \\
\cline { 2 - 10 } & Female & 13 & 15.7 & 70 & 84.3 & 83 & 100.0 & \\
\hline \multirow{2}{*}{ Age } & $\leq 30$ years & 7 & 16.3 & 36 & 83.7 & 43 & 100.0 & \multirow{2}{*}{0.387} \\
\cline { 2 - 9 } & $>30$ years & 7 & 12.3 & 50 & 87.7 & 57 & 100.0 & \\
\hline \multirow{2}{*}{ Economic class } & Classes B/C & 6 & 8.3 & 66 & 91.7 & 72 & 100.0 & \multirow{2}{*}{$0.014 *$} \\
\cline { 2 - 9 } & Classes D/E & 8 & 28.6 & 20 & 71.4 & 28 & 100.0 & \\
\hline \multirow{2}{*}{ Marital status } & Married & 8 & 17.0 & 39 & 8.3 & 47 & 100.0 & \multirow{2}{*}{0.297} \\
\cline { 2 - 8 } & Not married & 6 & 11.3 & 47 & 88.7 & 53 & 100.0 & \\
\hline
\end{tabular}

*statistically significant.

Table 2. Distribution of participants regarding disc displacement and joint problems (arthralgia, osteoarthritis and osteoarthrosis) according to gender, age, economic class and marital status.

\begin{tabular}{|c|c|c|c|c|c|c|c|c|c|c|c|c|c|c|c|}
\hline \multicolumn{2}{|c|}{ Variables } & \multicolumn{4}{|c|}{ Disc displacement } & \multicolumn{2}{|c|}{ Total } & \multirow{2}{*}{$\begin{array}{c}\text { p- } \\
\text { value }\end{array}$} & \multicolumn{4}{|c|}{ Joint problems } & \multicolumn{2}{|c|}{ Total } & \multirow{3}{*}{$\begin{array}{c}\text { p-value } \\
0.636\end{array}$} \\
\hline & & \multirow{2}{*}{\begin{tabular}{|c|} 
Yes \\
5
\end{tabular}} & \multirow{2}{*}{$\begin{array}{c}\mathbf{\%} \\
29.4\end{array}$} & \multirow{2}{*}{\begin{tabular}{|c|} 
No \\
12 \\
\end{tabular}} & \multirow{2}{*}{$\begin{array}{c}\% \\
70.6\end{array}$} & \multirow{2}{*}{$\begin{array}{c}\mathbf{n} \\
17\end{array}$} & \multirow{2}{*}{$\begin{array}{c}\% \\
100.0\end{array}$} & & Yes & $\%$ & No & $\%$ & $\mathrm{n}$ & $\%$ & \\
\hline \multirow{2}{*}{ Gender } & Male & & & & & & & \multirow{2}{*}{0.468} & 3 & 17.6 & 14 & 82.4 & 17 & 100.0 & \\
\hline & Female & 21 & 25.3 & 62 & 74.7 & 83 & 100.0 & & 15 & 18.1 & 68 & 81.9 & 83 & 100.0 & \\
\hline \multirow{2}{*}{ Age } & $\leq 30$ years & 15 & 34.9 & 28 & 65.1 & 43 & 100.0 & \multirow{2}{*}{0.064} & 10 & 23.3 & 33 & 76.7 & 43 & 100.0 & 0.177 \\
\hline & $>30$ years & 11 & 19.3 & 46 & 80.7 & 57 & 100.0 & & 8 & 14.0 & 49 & 86.0 & 57 & 100.0 & \\
\hline \multirow{2}{*}{ Economic class } & Classes B/C & 18 & 25.0 & 54 & 75.0 & 72 & 100.0 & \multirow{2}{*}{0.448} & 6 & 8.3 & 66 & 91.7 & 72 & 100.0 & $<0.001^{*}$ \\
\hline & Classes D/E & 8 & 28.6 & 20 & 71.4 & 28 & 100.0 & & 12 & 42.9 & 16 & 57.1 & 28 & 100.0 & \\
\hline \multirow{2}{*}{ Marital status } & Married & 16 & 34.0 & 31 & 66.0 & 47 & 100.0 & \multirow{2}{*}{0.067} & 11 & 23.4 & 36 & 76.6 & 47 & 100.0 & $0.014 *$ \\
\hline & Not married & 10 & 18.9 & 43 & 81.1 & 53 & 100.0 & & 7 & 13.2 & 46 & 86.8 & 53 & 100.0 & \\
\hline
\end{tabular}

\footnotetext{
*statistically significant.
} 
Table 3. Final logistic regression model for myofascial pain according to economic class, marital status, gender and age.

\begin{tabular}{|l|c|c|c|c|c|c|c|c|}
\hline & B & S.E. & Wald & df & $\begin{array}{c}\text { p- } \\
\text { value }\end{array}$ & \multirow{2}{*}{ OR } & \multicolumn{2}{|c|}{$\begin{array}{c}\text { L5\% CI for OR } \\
\text { limit }\end{array}$} \\
\hline Classes D/E & 1.469 & 0.623 & 5.553 & 1 & 0.018 & 4.345 & 1.280 & 14.746 \\
\hline Married & -0.702 & 0.626 & 1.259 & 1 & 0.262 & 0.495 & 0.145 & 1.690 \\
\hline Male & 0.771 & 1.122 & 0.472 & 1 & 0.492 & 2.163 & 0.240 & 19.506 \\
\hline$\leq 30$ years & -0.214 & 0.610 & 0.123 & 1 & 0.726 & 0.807 & 0.244 & 2.670 \\
\hline Constant & 1.291 & 0.571 & 5.104 & 1 & 0.024 & 3.635 & & \\
\hline Goodness of fit* & 0.439 & & & & & & & \\
\hline
\end{tabular}

* Determined using Hosmer-Lemeshow test.

Table 4. Final logistic regression model for joint problems according to economic class, gender, marital status and age.

\begin{tabular}{|l|c|c|c|c|c|c|c|c|}
\hline & B & S.E. & Wald & df & $\begin{array}{c}\text { p- } \\
\text { value }\end{array}$ & OR & \multicolumn{2}{|c|}{$\begin{array}{c}\text { L5\% CI for OR } \\
\text { limit }\end{array}$} \\
\hline Classes D/ E & 2.422 & 0.799 & 9.186 & 1 & 0.002 & 11.265 & 2.353 & 53.930 \\
\hline Male & -1.359 & 0.935 & 2.114 & 1 & 0.146 & 0.257 & 0.041 & 1.605 \\
\hline Married & -0.751 & 0.716 & 1.099 & 1 & 0.295 & 0.472 & 0.116 & 1.921 \\
\hline$\leq 30$ years & -0.596 & 0.701 & 0.722 & 1 & 0.396 & 0.551 & 0.139 & 2.179 \\
\hline Constant & -1.469 & 0.929 & 2.498 & 1 & 0.114 & 0.230 & & \\
\hline Goodness of fit* & 0.691 & & & & & & & \\
\hline
\end{tabular}

* Determined using Hosmer-Lemeshow test.

the determination of the profile of a given population and assisting in the establishment of public policies aimed at controlling and eradicating adverse health conditions. The different prevalence rates described for TMD in the literature may be explained by the complexity and multifactor etiology of this disorder $(1,20)$.

The prevalence of TMD in the present study (42\%) was determined based on any symptom listed on Axis 1 of the RDC/TMD in a sample made up mostly of women aged 30 years or older. However, no significant association was found between TMD and gender in this study, which is in disagreement with findings described in previous studies (8). A number of theories have been put forth to explain the predominance of the female gender in cases of TMD, including the influence of biological, emotional and cultural factors $(8,14)$. Among the biological factors which explain a greater association of TMD in women, the influence of genetic and hormonal factors have been mentioned in the literature (14).

The influence of socioeconomic factors on different health conditions is widely recognized. Individuals with higher incomes have greater access to information on health and preventive treatment, which can diminish the likelihood of disease progression. Such individuals are also less exposed to risk factors such as precarious housing, nutrient-poor foods, etc (1). In the present study, economic classes D and E (indicating lower economic status) were significantly associated with a greater prevalence of myofascial pain and joint problems (arthralgia, osteoarthritis and osteoarthrosis). One hypothesis for this finding would be exposure to risk factors such as precarious work conditions and food insecurity, which constitute stressors that may contribute to the development and perpetuation of TMD. Indeed, a number of studies have indicated stress and low socioeconomic status as important components of this disorder $(8-10,21,22)$.

The results of the present study and a brief review of the literature demonstrate the influence of socioeconomic/ demographic factors on TMD. However, these findings should be interpreted with caution, considering the size of the sample and the fact that the present investigation constitutes a pilot study, and it was a principal limitation of this study. Moreover, as the sampling procedure given for the pilot study was identical to the main study, the results probably will be the same.

This report describes the prevalence of TMD an how the RDC/TMD may continue to serve the function of 
guiding future research and, most importantly, serve as an evidence-based diagnostic and classification system to aid in the rational choice of clinical care for TMD sufferers around the world.

\section{Conclusion}

The present study suggest that poverty is a important condition to exhibit myofascial pain and joint problems.

\section{References}

1. Martins RJ, Garcia AR, Garbin CA, Sundefeld ML. The relation between socio-economic class and demographic factors in the occurrence of temporomandibular joint dysfunction. Cien Saude Colet. 2008;13:2089-2096.

2. Kitsoulis P, Marini A, Iliou K, Galani V, Zimpis A, Kanavaros $\mathrm{P}$, et al. Signs and symptoms of temporomandibular joint disorders related to the degree of mouth opening and hearing loss. BMC Ear Nose Throat Disord. 2011;11:1-8.

3. Guarda-Nardini L, Piccotti F, Mogno G, Favero L, Manfredini D. Age-related differences in temporomandibular disorder diagnoses. Cranio. 2012;30:103-9.

4. Rusanen J, Silvola AS, Tolvanen M, Pirttiniemi P, Lahti S, Sipilä K. Pathways between temporomandibular disorders, occlusal characteristics, facial pain, and oral health-related quality of life among patients with severe malocclusion. Eur J Orthod. 2012;34:512-7.

5. De Kanter RJ, Truin GJ, Burgersdijk RC, Van 't Hof MA, Battistuzzi PG, Kalsbeek H, et al. Prevalence in the Dutch adult population and a meta-analysis of signs and symptoms of temporomandibular disorder. J Dent Res. 1993;72:1509-1518.

6. Machado LP, Nery CeG, Leles CR, Nery MB, Okeson JP. The prevalence of clinical diagnostic groups in patients with temporomandibular disorders. Cranio. 2009;27:194-9.

7. Weiler RM, Santos FM, Kulic MA, De Souza Lima MP, Pardini SR, Mori M, et al. Prevalence of signs and symptoms of temporomandibular dysfunction in female adolescent athletes and non-athletes. Int J Pediatr Otorhinolaryngol. 2013;77:519-524.

8. Bagis B, Ayaz EA, Turgut S, Durkan R, Özcan M. Gender difference in prevalence of signs and symptoms of temporomandibular joint disorders: a retrospective study on 243 consecutive patients. Int J Med Sci. 2012;9:539-544.

9. Johansson A, Unell L, Carlsson G, Söderfeldt B, Halling A, Widar F. Associations between social and general health factors and symptoms related to temporomandibular disorders and bruxism in a population of 50-year-old subjects. Acta Odontol Scand. 2004;62:231-7.

10. Blanco-Hungría A, Rodríguez-Torronteras A, Blanco-Aguilera A, Biedma-Velázquez L, Serrano-Del-Rosal R, Segura-Saint-Gerons $\mathrm{R}$, et al. Influence of sociodemographic factors upon pain intensity in patients with temporomandibular joint disorders seen in the primary care setting. Med Oral Patol Oral Cir Bucal. 2012;17:e1034-1041.

11. Shi Q, Wang YY. Investigation of the prevalence of temporomandibular disorders in 352 aged edentulous individuals. Zhonghua Kou Qiang Yi Xue Za Zhi. 2012;47:19-21.

12. Kim BS, Kim YK, Yun PY, Lee E, Bae J. The effects of estrogen receptor $\alpha$ polymorphism on the prevalence of symptomatic temporomandibular disorders. J Oral Maxillofac Surg. 2010;68:2975-9.

13. Planello AC, Campos MI, Meloto CB, Secolin R, Rizatti-Barbosa $\mathrm{CM}$, Line SR, et al. Association of matrix metalloproteinase gene polymorphism with temporomandibular joint degeneration. Eur J Oral Sci. 2011;119:1-6.

14. Ribeiro-Dasilva MC, Peres Line SR, Leme Godoy dos Santos MC, Arthuri MT, Hou W, Fillingim RB, et al. Estrogen receptoralpha polymorphisms and predisposition to TMJ disorder. J Pain. 2009;10:527-533.

15. Oakley M, Vieira AR. The many faces of the genetics contribution to temporomandibular joint disorder. Orthod Craniofac Res. 2008;11:125-135.
16. Wu N, Hirsch C. Temporomandibular disorders in German and Chinese adolescents. J Orofac Orthop. 2010;71:187-198.

17. McMillan AS, Wong MC, Lee LT, Yeung RW. Depression and diffuse physical symptoms in southern Chinese with temporomandibular disorders. J Oral Rehabil. 2009;36:403-7.

18. Dworkin SF, Leresche L. Research diagnostic criteria for temporomandibular disorders. J Craniomandib Disord. 1992;6:301-355.

19. Manfredini D, Piccotti F, Ferronato G, Guarda-Nardini L. Age peaks of different RDC/TMD diagnoses in a patient population. Journal of Dentistry. 2010;38:392-9.

20. Wiesinger B, Malker H, Englund E, Wänman A. Does a doseresponse relation exist between spinal pain and temporomandibular disorders? BMC Musculoskelet Disord. 2009;10:28.

21. Kuttila M, Niemi PM, Kuttila S, Alanen P, Le Bell Y. TMD treatment need in relation to age, gender, stress, and diagnostic subgroup. J Orofac Pain. 1998;12:67-74.

22. Janal MN, Raphael KG, Nayak S, Klausner J. Prevalence of myofascial temporomandibular disorder in US community women. J Oral Rehabil. 2008;35:801-9.

\section{Author contributions}

B.G. MAGALHÃES took part in the project conception, data analysis and composition of the article. S.T. SOUZA gathered the pilot project data, made adjustments between the pilot and the study, took part in the gathering of data and the composition of the article. V.V.C. MELLO took part in the gathering of data, analysis of results and the composition of the article. A.C.S. BARBOSA, M.P.L.A. MORAIS took part in the project conception, analysis and discussion of the data, and the composition of the article. A.F. CALDAS JÚNIOR, M.M.V.B. VASCONCELOS took part in the revision and composition of the article. 